\title{
Commercial trials using emamectin benzoate to control sea lice Lepeophtheirus salmonis infestations in Atlantic salmon Salmo salar
}

\author{
J. Stone ${ }^{1, *}$, I. H. Sutherland ${ }^{2}$, C. Sommerville ${ }^{1}$, R. H. Richards ${ }^{1}$, K. J. Varma ${ }^{3}$ \\ 'Institute of Aquaculture, University of Stirling, Stirling FK9 4LA, Scotland, UK \\ ${ }^{2} 31 / 10$ Hermitage Drive, Edinburgh EH10 6BY, Scotland, UK \\ ${ }^{3}$ Schering-Plough Animal Health, Union, New Jersey 07083, USA
}

\begin{abstract}
Two trials were conducted at commercial salmon farms to evaluate the efficacy of emamectin benzoate (Slice, $0.2 \%$ aquaculture pre-mix, Schering-Plough Animal Health) as a treatment for sea lice Lepeophtheirus salmonis (Krøyer) and Caligus elongatus Nordmann infestations in Atlantic salmon Salmo salar L. Trials were carried out in $15 \mathrm{~m}^{2}$ commercial sea pens, at temperatures of 5.5 to $7.5^{\circ} \mathrm{C}$ and 10.8 to $13.8^{\circ} \mathrm{C}$. Each pen was stocked with 14000 to 17500 fish with mean weights of 0.44 to 0.74 and 1.33 to $1.83 \mathrm{~kg}$. Fish were naturally infested with sea lice at the start of each trial. At Day -1, samples of 10 or 15 fish were taken from each pen to determine pre-treatment numbers of lice. Emamectin benzoate was administered in feed, to 4 replicate pens, at a dose of $50 \mu \mathrm{g} \mathrm{kg}^{-1}$ biomass d ${ }^{-1}$ for 7 consecutive days (Days 0 to 6). Sea lice were counted again, between Days 7 and 77 , and comparisons made with untreated control fish. Despite adverse weather conditions, wide variations in fish weights and exposure to new infestations, treatment was effective against chalimus and motile stages of $L$. salmonis. In the autumn trial, efficacy at Day 27 was $89 \%$, and lice numbers remained lower on treated fish than on control fish $64 \mathrm{~d}$ from the start of treatment. In the winter trial, reductions in lice numbers at low temperatures were slower but good efficacy was achieved by Day 35. Although control fish had to be treated with hydrogen peroxide at Day 21, fish treated only with emamectin benzoate on Days 0 to 6 still had $89 \%$ fewer lice than control fish at Day 35. There were very few C. elongatus present, but at the end of both trials numbers were lower on treated fish. No adverse effects were associated with treatment of fish with emamectin benzoate.
\end{abstract}

KEY WORDS: Sea lice - Lepeophtheirus salmonis - Caligus elongatus - Salmo salar - Emamectin benzoate

\section{INTRODUCTION}

Infestations of sea lice are largely managed using a combination of chemical treatments and husbandry techniques, such as fallowing. Treatments by immersion bath are most widely used (Roth et al. 1993) and employ hydrogen peroxide (Salartect ${ }^{\circledR}$, Brenntag; Paramove ${ }^{\circledR}$, Solvay-Interox), the synthetic pyrethroids cypermethrin (Excis ${ }^{\circledR}$, Vericore) and deltamethrin (Alphamax ${ }^{\otimes}$, Alpharma) and the organophosphates

•E-mail: janet.stone@stir.ac.uk dichlorvos (Aquagard ${ }^{\circledR}$, Novartis) and azamethiphos (Salmosan ${ }^{\otimes}$, Novartis). Most of these are only effective against pre-adult and adult stages of sea lice, allowing chalimus stages to survive and continue the cycle of infestation, although cypermethrin is effective against immature stages (Jakobsen \& Holm 1990). Immersion treatments are difficult to apply during adverse weather conditions and on exposed sites, and the procedures involved are very stressful to fish. As a result, there is a growing trend towards the development of treatments that can be administered in feed. Ivermectin has been used as an in-feed treatment (Johnson \& Margolis 1993, Smith et al. 1993) but is not licensed 
for use in fish in the United Kingdom and can only be prescribed under the cascade procedure (Anonymous 1998), where authorised products failed to provide effective control. Diflubenzuron (Lepsidon ${ }^{\circledR}$, Ewos) (Erdal 1997) and teflubenzuron (Calicide ${ }^{\otimes}$, Nutreco) (Ritchie 1996) can be also used as in-feed treatments for sea lice. These insect growth regulators inhibit chitin synthesis (Horst \& Walker 1996) and, although effective against moulting stages, efficacy against adult stages is reduced (Ritchie 1996).

The efficacy of emamectin (4"-deoxy-4"epimethylaminoavermectin $B_{1}$ ) benzoate as an oral treatment for sea lice Lepeophtheirus salmonis (Krøyer) and Caligus elongatus Nordmann infestations in Atlantic salmon has been demonstrated in tank and experimental field trials (Stone et ai. 1999, 2000a). A therapeutic dose rate of $50 \mu \mathrm{g} \mathrm{kg}^{-1} \mathrm{~d}^{-1}$ for $7 \mathrm{~d}$ was selected and found to be highly effective against the chalimus and adult stages of both species of sea lice found in Scotland. The aim of the current study was to investigate the use of emamectin benzoate as a $0.2 \%$ aqauculture pre-mix (Slice ${ }^{\circledast}$, Schering-Plough Animal Health, Union, USA) under normal working conditions at commercial farms on the West Coast of Scotland. Owing to size variations in fish populations, these conditions present greater potential for different rates of drug uptake than those found in laboratory tank trials. The first study evaluated the treatment of fish in their first year at sea and the second study examined larger fish in their second year at sea, under very extreme weather conditions and at low water temperatures.

\section{MATERIALS AND METHODS}

Fish and holding conditions. The trials were carried out on commercial salmon farms on the West Coast of Scotland. At both sites, there were 30 pens measuring $15 \mathrm{~m} \times 15 \mathrm{~m} \times 8 \mathrm{~m}$ deep, each stocked with 14000 to 17500 Atlantic salmon. Fish were all naturally infested with Lepeophtheirus salmonis and Caligus elongatus at the time of selection and were exposed throughout the trial to re-infestation by larval sea lice derived from fish in adjoining pens at the site.

Experimental design. Winter trial: Eight pens were selected for the trial and split into 4 replicate blocks, each with 1 control and 1 treated group allocated at random (Fig. 1). Replicate blocks were selected on the basis of proximity to each other and pens in each block were of similar biomass. The pens were stocked with fish of the same year class in April 1996, and the trial was started in February 1997. Surface water temperatures over the trial period were 5.5 to $7.5^{\circ} \mathrm{C}$ and salinity 17.5 to $32 \mathrm{ppt}$, although at a depth of $1 \mathrm{~m}$ the ranges were only 7.0 to $7.5^{\circ} \mathrm{C}$ and 24.5 to 32.0 ppt. Pre-treatment, mean fish weights in each pen were 1.33 to $1.83 \mathrm{~kg}$ and individual fish weights ranged from 0.45 to $2.82 \mathrm{~kg}$. The sample size used for parasite enumeration was 5 or 15 fish per pen.

Autumn trial: Twelve pens, located at one end of the site, were treated with emamectin benzoate (Fig. 2). Four of these treated pens were selected for evaluation of lice numbers and 4 pens, which received an unmedicated ration, were randomly selected as control

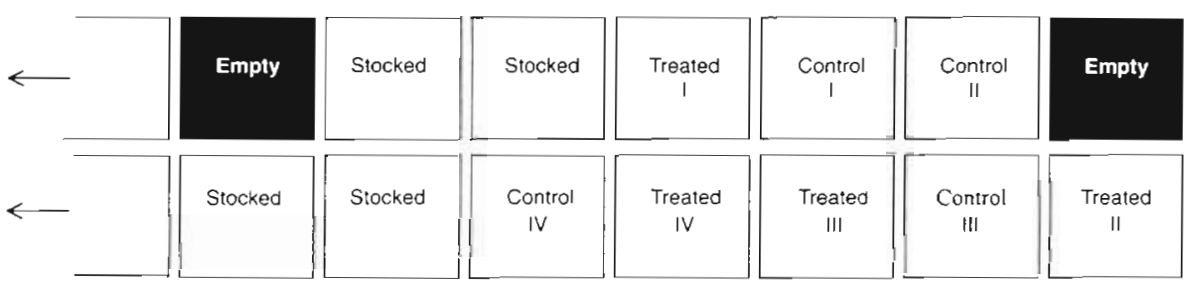

Fig. 1. Winter trial: Plan of pens at the study site showing the positions of the 4 control and 4 treated pens. There were 36 pens, 30 of which were stocked with 14000 to 17500 fish. Black pens were not stocked with fish. There were 2 more pontoons of pens in close proximity to the study site

\begin{tabular}{|c|c|c|c|c|c|c|c|c|c|c|c|c|c|c|}
\hline $\begin{array}{c}\text { Treated } \\
\text { III }\end{array}$ & Treated & Treated & Ireated & & Treated & $\begin{array}{c}\text { Treated } \\
1\end{array}$ & Stock & Stock & & Stock & $\begin{array}{c}\text { Control } \\
\text { I }\end{array}$ & Slock & $\begin{array}{c}\text { Control } \\
\text { II }\end{array}$ & \\
\hline & $\begin{array}{c}\text { Treated } \\
\text { IV }\end{array}$ & Treated & Treated & Treated & & Treated & $\begin{array}{c}\text { Treated } \\
\text { If }\end{array}$ & Stock & $\begin{array}{c}\text { Control } \\
\text { IV }\end{array}$ & & Stock & Stock & $\begin{array}{c}\text { Control } \\
\text { III }\end{array}$ & Stack \\
\hline
\end{tabular}

Fig. 2. Autumn trial: Plan of pens at the study site showing the positions of the 4 control pens and the pens treated with emamectin benzoate. There was a total of 36 pens, of which 30 were stocked with 14000 to 17500 fish. Labels in bold are the replicate pens evaluated for sea lice at Days -1,13,27 and 77. Sampling by site staff on Days 34 to 72 was carried out in 1 treated and 1 control pen. Black pens were not stocked with fish. There were 3 more pontoons of pens within $1 \mathrm{~km}$ of the study site 
groups. The pens were stocked with fish in February 1997 and the trial started in September. Over the main trial period, from Day 0 to Day 21, the water temperature was 11.5 to $13.8^{\circ} \mathrm{C}$ and between Days 27 and 77 temperatures fell from 11.7 to $10.8^{\circ} \mathrm{C}$. The surface salinity was 13.0 to $31.5 \mathrm{ppt}$, although at a depth of $4 \mathrm{~m}$ the lowest salinity recorded was $18.0 \mathrm{ppt}$. Pre-treatment mean fish weights in each pen ranged from 0.44 to $0.74 \mathrm{~kg}$. The sample size used for parasite enumeration was 5 or 10 fish per pen.

Medicated feed: The biomass for medication was determined from the mean weight of fish for each pen, based on a sample of 100 fish per pen, multiplied by the total number of fish. This was then used to calculate predicted mean weights at Day 0 based on historical growth data. The basal rations used were 9 or $5 \mathrm{~mm}$ (Fulmar feeds, BOCM Pauls Ltd, Renfrew, UK) salmon feed pellets. Feeds were medicated using $0.2 \%$ emamectin benzoate pre-mix (Slice ${ }^{\circledR}$ ) to give a nominal dose of $50 \mu \mathrm{g} \mathrm{kg}^{-1}$ fish biomass $\mathrm{d}^{-1}$. In the winter trial, the feed rate was $0.4 \%$ biomass $\mathrm{d}^{-1}$ and pre-mix was therefore incorporated at a rate of $6.25 \mathrm{~kg} \mathrm{t}^{-1}$ feed. In the autumn trial, fish were fed at $1.0 \%$ biomass $\mathrm{d}^{-1}$ and pre-mix was added at a rate of $2.5 \mathrm{~kg} \mathrm{t}^{-1}$ feed. Medicated feed was administered for a period of 7 consecutive days (Days 0 to 6 ). Control fish received the same basal ration without emamectin benzoate. Feeding rates and methods were identical for control and treated groups in each trial.

Evaluation of sea lice. In the winter trial, 15 fish were randomly selected from each trial pen on Days -1, 7, 14 and 21. Each fish was examined with a hand lens and all lice removed and fixed in $5 \%$ formalin. Lice were identified as Lepeophtheirus salmonis or Caligus elongatus and the number of chalimus stages I, II, III, IV, pre-adult I, pre-adult II and adults recorded. Pre-adult and adult lice were also identified as males or females. Additional counts were conducted on Days 28 and 35, when 5 fish from each pen were anaesthetised and the number of lice counted in situ, but chalimus and pre-adults were not distinguished by stage. In the autumn trial, 10 fish were sampled from each pen and lice were counted in situ, as described above, on Days -1, 13, 27 and 77. Additional counts were conducted by experienced farm staff on Days 34,42,49,54,64 and 72, when only 5 fish from a single control pen and a single treated pen were sampled. Records of sea lice damage on fish were based on visual assessment of typical epidermal lesions.

Other treatments. On Day 21 in the winter trial, the whole site, including the 4 control pens, was treated with hydrogen peroxide owing to high lice burdens. The 4 pens treated with emamectin benzoate were not treated at this time.
Data handling. Parasite counts were summarised as chalimus (copepodites, chalimus stages I, II, III and IV), motile lice (pre-adult and adult stages) and total lice (chalimus and motile stages combined) and the arithmetic means calculated. Parasite count data from the winter trial were subjected to F-tests for homogeneity of variances and a correlation test to examine the normality of distribution. Lice numbers were then analysed using the non-parametric STP test (Sokal \& Rohlf 1981). The efficacy or percentage reduction in mean sea lice, relative to the control groups, was calculated as follows:

$$
\% \text { efficacy }=100-\left(100 \times \frac{\text { mean of treated replicates }}{\text { mean of control replicates }}\right)
$$

Adverse effects. Records were maintained of the number of fish mortalities in each pen during the trial period. Fish were observed for any changes in behaviour and appearance such as lethargy, loss of appetite, abnormal swimming behaviour or dark colouration. Any external abnormalities were recorded when fish were sampled for sea lice.

\section{RESULTS}

\section{Winter trial}

In the winter trial, feed consumption appeared to be satisfactory; however, stormy weather conditions on Days 3 and 5 hampered observation of fish feeding responses during the medication period. Previous trials with emamectin benzoate have shown no problems with acceptability of medicated feed. There was no increase in fish mortality following treatment and no adverse effects were observed.

\section{Efficacy against Lepeophtheirus salmonis}

The efficacy and mean numbers of Lepeophtheirus salmonis per fish are shown in Table 1. On Day -1 , control pen II had significantly $(p<0.05)$ fewer lice than treated pen II while control pen III had significantly more lice than treated pen III. However, all trial pens had high numbers of lice at the start of the trial and there were no significant differences between control and treated pens in replicate blocks I and IV.

Lepeophtheirus salmonis numbers remained high in the control groups over the trial period. In the treated groups numbers decreased overall by $54.5 \%$ from Day -1 to Day 21. At Day 21, the number of L. salmonis on control fish ranged from 5 to 80 while the range on treated fish was 5 to 31 and all 4 treated pens had sig- 
Table 1. Winter trial: Efficacy of emamectin benzoate against natural infestations of Lepeophtheirus salmonis on Atlantic salmon. Fish received medicated feed at the rate of $0.4 \%$ biomass $\mathrm{d}^{-1}$ for 7 consecutive days (Days 0 to 6 ). Sample size $\mathrm{N}=15$ fish per pen. Sea temperature 7.0 to $7.5^{\circ} \mathrm{C}$ at a depth of $1 \mathrm{~m}$

\begin{tabular}{|c|c|c|c|c|c|}
\hline Time & $\begin{array}{c}\text { Nominal dose } \\
\mu \mathrm{g} \mathrm{kg}{ }^{-1} \text { (replicate) }\end{array}$ & $\begin{array}{l}\text { Mean chalimus } \\
\qquad( \pm \mathrm{SD})\end{array}$ & $\begin{array}{l}\text { Mean motiles } \\
( \pm \mathrm{SD})\end{array}$ & $\begin{array}{l}\text { Mean total lice } \\
\qquad( \pm S D)\end{array}$ & $\begin{array}{l}\% \text { efficacy relative } \\
\text { to controls (total lice) }\end{array}$ \\
\hline \multirow[t]{8}{*}{ Day -1} & $0(\mathrm{I})$ & $8.5 \pm 4.8$ & $17.5 \pm 5.2$ & $26.1 \pm 6.9$ & \multirow{8}{*}{-} \\
\hline & 0 (II) & $9.1 \pm 5.1$ & $31.1 \pm 7.3$ & $40.2 \pm 11.6$ & \\
\hline & 0 (III) & $11.9 \pm 8.4$ & $33.3 \pm 8.7$ & $45.1 \pm 12.8$ & \\
\hline & 0 (IV) & $5.7 \pm 3.7$ & $24.3 \pm 6.8$ & $29.9 \pm 8.5$ & \\
\hline & $50(\mathrm{I})$ & $5.7 \pm 4.8$ & $16.5 \pm 5.5$ & $22.2 \pm 7.7$ & \\
\hline & 50 (II) & $12.3 \pm 6.7$ & $43.9 \pm 14.7$ & $56.1 \pm 19.1$ & \\
\hline & 50 (III) & $7.2 \pm 5.1$ & $22.3 \pm 9.5$ & $29.5 \pm 12.3$ & \\
\hline & 50 (IV) & $5.3 \pm 3.7$ & $26.1 \pm 9.3$ & $31.3 \pm 11.7$ & \\
\hline \multirow[t]{8}{*}{ Day 7} & $0(\mathrm{I})$ & $6.9 \pm 5.0$ & $21.3 \pm 9.0$ & $28.1 \pm 13.0$ & \multirow{8}{*}{20.8} \\
\hline & $0(I I)$ & $9.1 \pm 5.2$ & $39.9 \pm 15.4$ & $48.9 \pm 19.7$ & \\
\hline & $O$ (III) & $8.3 \pm 4.9$ & $38.8 \pm 11.3$ & $47.1 \pm 13.0$ & \\
\hline & 0 (IV) & $6.7 \pm 4.0$ & $32.6 \pm 8.7$ & $39.3 \pm 11.0$ & \\
\hline & $50(I)$ & $5.2 \pm 3.2$ & $16.7 \pm 5.5$ & $21.9 \pm 6.8$ & \\
\hline & 50 (II) & $11.2 \pm 9.7$ & $37.3 \pm 11.1$ & $48.5 \pm 17.2$ & \\
\hline & 50 (III) & $3.5 \pm 2.5$ & $23.6 \pm 5.6$ & $27.1 \pm 6.7$ & \\
\hline & 50 (IV) & $4.9 \pm 2.8$ & $27.1 \pm 10.4$ & $31.9 \pm 13.0$ & \\
\hline \multirow[t]{8}{*}{ Day 14} & $O(I)$ & $4.7 \pm 3.0$ & $17.0 \pm 5.6$ & $21.7 \pm 7.2$ & \multirow{8}{*}{36.1} \\
\hline & $O(\mathrm{II})$ & $6.2 \pm 6.0$ & $36.4 \pm 13.2$ & $42.6 \pm 17.1$ & \\
\hline & $O$ (III) & $4.7 \pm 3.8$ & $34.9 \pm 10.1$ & $39.5 \pm 12.1$ & \\
\hline & 0 (IV) & $4.9 \pm 3.0$ & $35.1 \pm 13.3$ & $40.0 \pm 14.8$ & \\
\hline & $50(\mathrm{I})$ & $3.2 \pm 1.8$ & $11.3 \pm 5.0$ & $14.5 \pm 6.0$ & \\
\hline & 50 (II) & $4.4 \pm 4.0$ & $28.1 \pm 5.8$ & $32.5 \pm 7.4$ & \\
\hline & 50 (III) & $2.9 \pm 2.9$ & $17.9 \pm 6.9$ & $20.8 \pm 8.3$ & \\
\hline & 50 (IV) & $3.3 \pm 2.9$ & $20.9 \pm 9.0$ & $24.2 \pm 10.7$ & \\
\hline \multirow[t]{8}{*}{ Day 21} & $0(\mathrm{I})$ & $3.1 \pm 1.9$ & $17.3 \pm 8.1$ & $20.4 \pm 8.5$ & \multirow{8}{*}{59.4} \\
\hline & 0 (II) & $5.8 \pm 3.9$ & $44.4 \pm 16.4$ & $50.2 \pm 17.1$ & \\
\hline & 0 (III) & $5.4 \pm 3.7$ & $45.4 \pm 14.1$ & $50.3 \pm 15.1$ & \\
\hline & 0 (IV) & $4.3 \pm 2.6$ & $29.8 \pm 11.8$ & $34.1 \pm 13.4$ & \\
\hline & 50 (I) & $4.8 \pm 2.6$ & $9.8 \pm 5.3$ & $14.6 \pm 6.0$ & \\
\hline & 50 (II) & $4.3 \pm 2.9$ & $16.3 \pm 6.7$ & $20.5 \pm 6.6$ & \\
\hline & 50 (III) & $1.8 \pm 1.5$ & $12.0 \pm 6.1$ & $13.8 \pm 6.6$ & \\
\hline & 50 (IV) & $2.0 \pm 1.1$ & $12.1 \pm 4.9$ & $14.1 \pm 5.5$ & \\
\hline
\end{tabular}

nificantly $(p<0.05)$ fewer lice than their corresponding control pens in each replicate block.

Over 3 d, from Day 20 to 22 , the entire site, except the 4 pens treated with emamectin benzoate, where fish had lower lice burdens and improved appearance, was given a hydrogen peroxide bath treatment. Observation of control fish shortly afterwards showed that many motile lice remained present on the peroxide treated fish. Additional sampling, at Day 28, confirmed motile lice numbers on control fish were reduced by only $25.5 \%$ between Days 21 and 28 (Table 2). Over the same period, chalimus numbers increased on control fish and this resulted in a further increase in motile lice by Day 35 (Fig. 3). In contrast, chalimus and motile numbers continued to fall on fish treated only with emamectin benzoate, and at Day 35 total lice numbers were $89.3 \%$ lower than on control fish. The range of lice on control fish was 4 to 33 while the range on treated fish was only 0 to 5 . At Day 21, copepodites and chalimus stages I, II and III were all reduced relative to the control groups, but the mean number of chalimus IV was slightly higher. Efficacy against adult male and adult female lice was 49 and $59 \%$ respectively while the greatest reduction was in pre-adult stages I and II (94\%). At Day 21, fish in all 4 control groups showed signs of lice damage with 33 to $80 \%$ of fish in each pen having dorsal, cranial or ventral lesions associated with sea lice activity, whereas only 0 to $7 \%$ of treated fish examined were affected.

\section{Efficacy against Caligus elongatus}

Possibly because of low water temperatures, there were very few Caligus elongatus present on any of the 
Table 2. Winter trial: Efficacy of emamectin benzoate against natural infestations of Lepeophtheirus salmonis on Atlantic salmon on Days 28 and 35 after control fish were treated with hydrogen peroxide at Day 21. Sample size $N=5$ fish per pen. Sea temperature 7.0 to $7.5^{\circ} \mathrm{C}$ at a depth of $1 \mathrm{~m}$

\begin{tabular}{|c|c|c|c|c|c|}
\hline Time & $\begin{array}{c}\text { Nominal dose } \\
\mu g \mathrm{~kg}^{-1} \text { (replicate) }\end{array}$ & $\begin{array}{c}\text { Mean chalimus } \\
( \pm S D)\end{array}$ & $\begin{array}{c}\text { Mean motiles } \\
\quad( \pm S D)\end{array}$ & $\begin{array}{l}\text { Mean total lice } \\
( \pm \mathrm{SD})\end{array}$ & $\begin{array}{l}\% \text { efficacy relative } \\
\text { to controls (total lice) }\end{array}$ \\
\hline \multirow[t]{8}{*}{ Day 28} & $0(\mathrm{I})$ & $8.0 \pm 2.2$ & $9.4 \pm 2.6$ & $17.4 \pm 3.6$ & \multirow{8}{*}{74.6} \\
\hline & 0 (II) & $20.2 \pm 15.0^{\mathrm{a}}$ & $7.2 \pm 5.1$ & $27.4 \pm 18.6$ & \\
\hline & 0 (III) & $11.8 \pm 3.3$ & $10.0 \pm 2.9$ & $21.8 \pm 3.6$ & \\
\hline & 0 (IV) & $12.8 \pm 5.5$ & $10.8 \pm 2.8$ & $23.6 \pm 8.0$ & \\
\hline & $50(\mathrm{I})$ & $1.0 \pm 1.0$ & $2.2 \pm 1.6$ & $3.2 \pm 1.1$ & \\
\hline & 50 (II) & $3.8 \pm 4.2$ & $6.4 \pm 5.4$ & $10.2 \pm 9.5$ & \\
\hline & 50 (III) & $1.6 \pm 2.1$ & $2.6 \pm 1.1$ & $4.2 \pm 1.6$ & \\
\hline & 50 (IV) & $1.8 \pm 2.5$ & $5.4 \pm 1.1$ & $7.2 \pm 1.6$ & \\
\hline \multirow[t]{8}{*}{ Day 35} & $0(I)$ & $4.8 \pm 1.1$ & $16.0 \pm 9.7$ & $20.8 \pm 10.3$ & \multirow{8}{*}{89.3} \\
\hline & 0 (II) & $7.0 \pm 3.8$ & $9.6 \pm 5.0$ & $16.6 \pm 8.4$ & \\
\hline & 0 (III) & $5.0 \pm 0.7$ & $8.2 \pm 3.6$ & $13.2 \pm 3.4$ & \\
\hline & 0 (IV) & $8.6 \pm 2.7$ & $15.2 \pm 4.9$ & $23.8 \pm 6.8$ & \\
\hline & $50(\mathrm{I})$ & $1.2 \pm 1.3$ & $0.8 \pm 0.8$ & $2.0 \pm 2.0$ & \\
\hline & 50 (II) & $0.8 \pm 0.8$ & $1.2 \pm 1.1$ & $2.0 \pm 1.9$ & \\
\hline & 50 (III) & $1.0 \pm 0.7$ & $1.2 \pm 1.1$ & $2.2 \pm 1.6$ & \\
\hline & 50 (IV) & $0.2 \pm 0.4$ & $1.6 \pm 0.5$ & $1.8 \pm 0.4$ & \\
\hline \multicolumn{6}{|c|}{ ancludes 1 fish with 42 chalimus } \\
\hline
\end{tabular}

fish sampled. At the start of the trial, there was a mean of 0.3 to $0.6 \mathrm{C}$. elongatus per fish in both the control and treated groups. At Day 21, the means were 0.3 to 1.1 per fish in the control groups and 0.1 to 0.2 per fish in the treated groups.

\section{Autumn trial}

In the autumn trial, the water was calm and clear and good feed consumption was observed in control and treated pens. Again there was no increase in fish mortality and no adverse effects were attributed to treatment.

\section{Efficacy against Lepeophtheirus salmonis}

The efficacy and mean numbers of Lepeophtheirus salmonis per fish are shown in Table 3 . The numbers of L. salmonis on control fish remained relatively low throughout the trial period. At Day 27, 0 to $20 \%$ of control fish in each pen had no chalimus or motile stages of L. salmonis, although 60 to $90 \%$ of treated fish had no L. salmonis present. At this time, mean lice numbers were $89.3 \%$ lower on treated fish than on control fish. At Day 77 a reduction of $16.7 \%$ was still evident.

In addition to the counts specified in the trial protocol, farm staff conducted their routine sea lice monitor- ing with counts of 5 fish from 1 control and 1 treated pen, as shown in Table 4. Though this was a less rigorous evaluation, it demonstrated that emamectin benzoate maintained its efficacy with reductions of more than $90 \%$ up to Day 64 . Chalimus and motile lice numbers increased gradually on control fish between days 34 and 72 , but on treated fish chalimus numbers remained low until Day 72, when there was also a marked increase in the number of motile lice. At Day 77, when all 8 trial pens were sampled again, lice numbers were still lower on treated fish than on control fish (Table 3) but efficacy had declined to $16.7 \%$. At Day 77, once lice numbers had increased on treated fish, there were still fewer adult male and female lice than on control fish and again efficacy was slightly higher against adult females $(63 \%)$ than against adult males (42\%). Only 14 to $29 \%$ of female lice on treated fish were gravid compared to 48 to $71 \%$ on control fish.

\section{Efficacy against Caligus elongatus}

Prior to the start of treatment, the mean numbers of Caligus elongatus were 1.7 to 4.5 in the control groups and 2.1 to 7.5 in the treated groups. Over the trial period numbers fell in the control groups to 1.9 to 3.7 at Day 13 and 0.1 to 1.4 at Day 27. No C. elongatus were found on any of the treated fish sampled at Days 13 and 27 . 


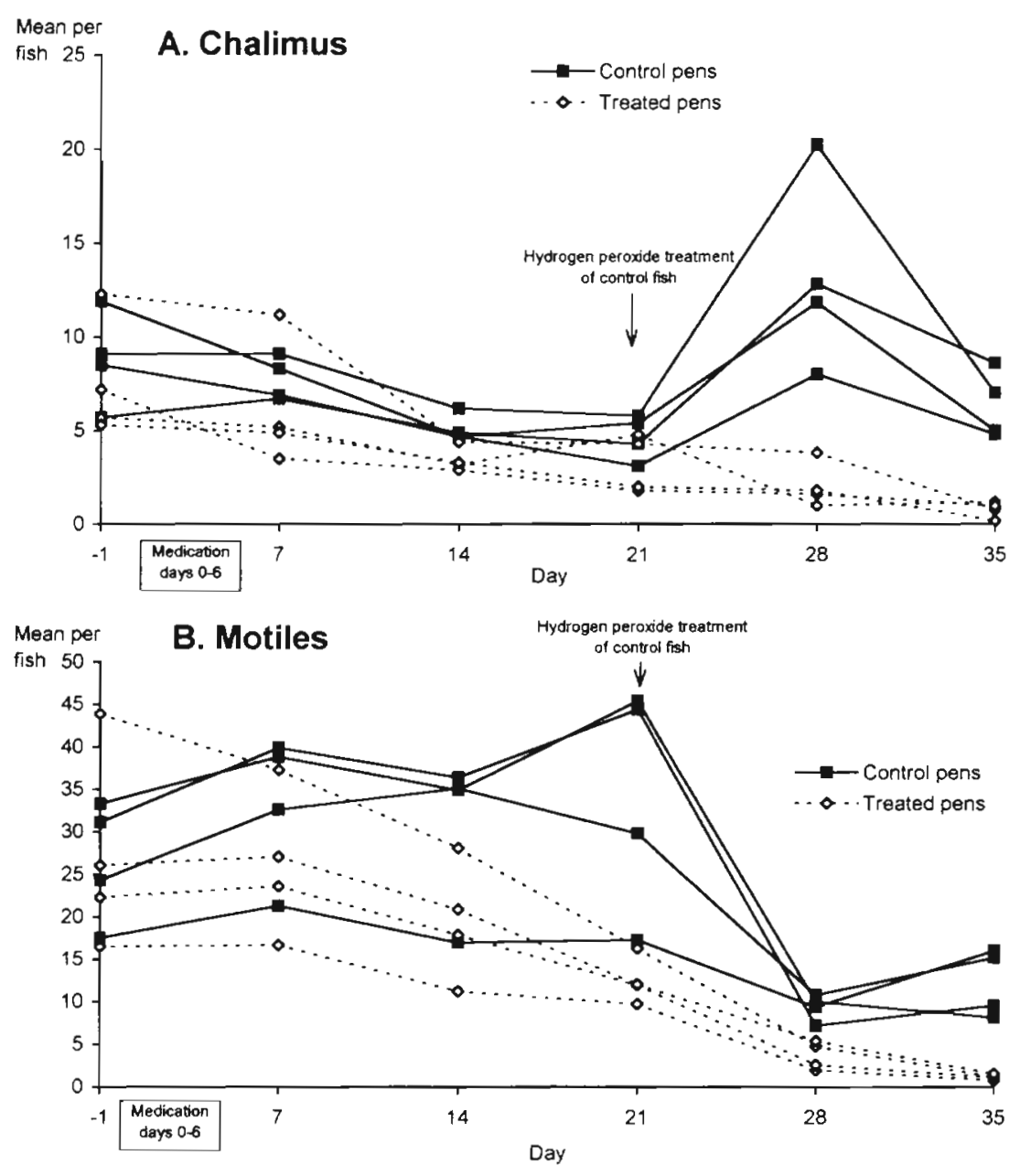

Fig. 3. Winter trial: Efficacy of emamectin benzoate against natural infestations of Lepeophtheirus salmonis on Atlantic salmon. Fish received medicated feed at $0.4 \%$ biomass $d^{-1}$ for 7 consecutive days (Days 0 to 6 ). $N=15$ on Days $-1,7,14$ and $21 ; N=5$ on Days 28 and 35. Pens treated with emamectin benzoate were not treated with hydrogen peroxide at Day 21 . Sea temperature 7.0 to $7.5^{\circ} \mathrm{C}$

\section{DISCUSSION}

Good efficacy was achieved against Lepeophtheirus salmonis in both trials and lice numbers were reduced by up to $89 \%$ at 27 and $35 \mathrm{~d}$ after the start of medication. In the winter trial, treated fish still had relatively high mean numbers of lice at Day 21 from the start of treatment, and efficacy was only $59 \%$ relative to the control groups. Further sampling showed the number of lice continued to decline on treated fish and efficacy of $89.3 \%$ was reached at Day 35 , the last day of counting. This contrasts with the results seen in 2 experimental field trials, carried out at temperatures of 13 to $15.5^{\circ} \mathrm{C}$, where at Day 21 treated fish had means of only 0.6 and 1.4 lice per fish and efficacy was as high as 91 to $99 \%$ (Stone et al. 2000a). However, in another trial, conducted at temperatures of 7.2 to $8.5^{\circ} \mathrm{C}$, treated fish still had means of 5.6 to 8.3 lice per fish at Day 21 although, owing to very high lice numbers on control fish, the efficacy was $89.7 \%$. At Day 55, under conditions of heavy copepodite settlement, motile lice numbers were still $86 \%$ lower than on control fish (Stone et al. 2000a). From the results of this trial and the experimental field trials, it appears that treatment at low temperatures still results in good efficacy although reductions in lice numbers may be slower.

In the winter trial, chalimus numbers fell on both the control and treated fish between Day -1 and Day 21 , but at Day 21 treated fish had fewer motile lice than control fish, although numbers of chalimus were similar. The reduction in chalimus on control fish was most likely a result of the existing chalimus maturing to motile stages and the absence of newly recruited copepodites to replace them. Low copepodite settlement might be associated with low temperatures and salinity over that period and sea lice populations tend to show 
marked seasonal variations in reproductive output (Ritchie et al. 1993, Wadsworth et al. 1998). Tank studies, using induced infestations of sea lice, have shown that treatment with emamectin benzoate arrested the development of chalimus stages, with some remaining attached by the frontal filament (Stone et al. 1999). This may account for the persistence of chalimus on treated fish in this study at Day 1. On Days 28 and 35,

Table 3. Autumn trial: Efficacy of emamectin benzoate against natural infestations of Lepeophtheirus salmonis on Atlantic salmon. Fish received medicated feed at the rate of $1.0 \%$ biomass $\mathrm{d}^{-1}$ for 7 consecutive days (Days 0 to 6 ). Sample size $\mathrm{N}=$ 10 fish per pen. Sea temperature 10.8 to $13.8^{\circ} \mathrm{C}$

\begin{tabular}{|c|c|c|c|c|c|}
\hline Time & $\begin{array}{c}\text { Nominal dose } \\
\mu \mathrm{kg}^{-1} \text { (replicate) }\end{array}$ & $\begin{array}{c}\text { Mean chalimus } \\
( \pm \mathrm{SD})\end{array}$ & $\begin{array}{l}\text { Mean motiles } \\
\quad( \pm \mathrm{SD})\end{array}$ & $\begin{array}{c}\text { Mean total lice } \\
( \pm \text { SD })\end{array}$ & $\begin{array}{l}\% \text { efficacy relative } \\
\text { to controls (total lice) }\end{array}$ \\
\hline \multirow[t]{8}{*}{ Day - 1} & $0(\mathrm{I})$ & $0.5 \pm 0.5$ & $2.1 \pm 3.5$ & $2.6 \pm 3.4$ & \multirow{8}{*}{ - } \\
\hline & 0 (II) & $0.7 \pm 1.1$ & $2.6 \pm 2.6$ & $3.3 \pm 2.8$ & \\
\hline & 0 (III) & $0.7 \pm 1.1$ & $1.3 \pm 4.1$ & $2.0 \pm 2.1$ & \\
\hline & 0 (IV) & $0.4 \pm 0.7$ & $1.2 \pm 2.1$ & $1.6 \pm 2.2$ & \\
\hline & $50(\mathrm{I})$ & $0.5 \pm 0.7$ & $1.7 \pm 2.4$ & $2.2 \pm 2.4$ & \\
\hline & 50 (II) & $0.5 \pm 1.0$ & $2.7 \pm 4.9$ & $3.2 \pm 2.9$ & \\
\hline & 50 (III) & $0.9 \pm 0.6$ & $2.6 \pm 4.8$ & $3.5 \pm 1.6$ & \\
\hline & 50 (IV) & $1.0 \pm 0.8$ & $4.0 \pm 2.3$ & $5.0 \pm 2.3$ & \\
\hline \multirow[t]{8}{*}{ Day 13} & 0 (I) & $0.2 \pm 0.4$ & $2.3 \pm 1.9$ & $2.5 \pm 1.8$ & \multirow{8}{*}{77.4} \\
\hline & 0 (II) & $0.7 \pm 0.7$ & $2.6 \pm 2.4$ & $3.3 \pm 2.8$ & \\
\hline & 0 (III) & $0.4 \pm 0.5$ & $2.9 \pm 2.0$ & $3.3 \pm 2.4$ & \\
\hline & 0 (IV) & $0.8 \pm 0.6$ & $2.5 \pm 1.9$ & $3.3 \pm 1.9$ & \\
\hline & 50 (I) & 0 & $0.7 \pm 1.1$ & $0.7 \pm 1.1$ & \\
\hline & 50 (II) & $0.1 \pm 0.3$ & $0.8 \pm 1.0$ & $0.9 \pm 1.2$ & \\
\hline & 50 (III) & 0 & $0.2 \pm 0.4$ & $0.2 \pm 0.4$ & \\
\hline & 50 (IV) & $0.2 \pm 0.4$ & $0.9 \pm 0.7$ & $1.1 \pm 0.7$ & \\
\hline \multirow[t]{8}{*}{ Day 27} & $0(\mathrm{I})$ & $0.1 \pm 0.3$ & $2.4 \pm 2.1$ & $2.5 \pm 2.1$ & \multirow{8}{*}{89.3} \\
\hline & 0 (II) & $2.0 \pm 1.3$ & $3.3 \pm 1.8$ & $4.3 \pm 2.1$ & \\
\hline & 0 (III) & $0.1 \pm 0.3$ & $2.2 \pm 1.6$ & $2.3 \pm 1.6$ & \\
\hline & 0 (IV) & $0.2 \pm 0.4$ & $1.8 \pm 1.8$ & $1.0 \pm 1.9$ & \\
\hline & 50 (I) & 0 & $0.1 \pm 0.3$ & $0.1 \pm 0.3$ & \\
\hline & 50 (II) & 0 & $0.2 \pm 0.5$ & $0.3 \pm 0.5$ & \\
\hline & 50 (III) & 0 & $0.3 \pm 0.5$ & $0.4 \pm 0.5$ & \\
\hline & 50 (IV) & 0 & $0.3 \pm 0.7$ & $0.3 \pm 0.7$ & \\
\hline \multirow[t]{8}{*}{ Day 77} & $0(\mathrm{I})$ & $3.8 \pm 2.5$ & $11.6 \pm 3.5$ & $15.4 \pm 4.4$ & \multirow{8}{*}{16.7} \\
\hline & 0 (II) & $9.9 \pm 4.2$ & $31.3 \pm 7.4$ & $41.2 \pm 8.7$ & \\
\hline & 0 (III) & $5.6 \pm 3.6$ & $20.4 \pm 10.9$ & $25.9 \pm 13.8$ & \\
\hline & 0 (IV) & $4.4 \pm 3.4$ & $21.1 \pm 11.2$ & $25.5 \pm 13.2$ & \\
\hline & $50(\mathrm{I})$ & $4.9 \pm 4.0$ & $13.2 \pm 13.5$ & $18.1 \pm 16.6$ & \\
\hline & 50 (II) & $12.3 \pm 5.0$ & $22.8 \pm 12.5$ & $35.1 \pm 14.5$ & \\
\hline & 50 (III) & $5.0 \pm 2.9$ & $14.2 \pm 13.0$ & $19.2 \pm 15.3$ & \\
\hline & 50 (IV) & $3.7 \pm 3.5$ & $13.8 \pm 12.0$ & $17.5 \pm 14.4$ & \\
\hline
\end{tabular}

Table 4. Autumn trial: Efficacy of emamectin benzoate against natural infestations of Lepeophtheirus salmonis on Atlantic salmon at Days 34 to 72. Counts conducted independently by site staff. Sample size $N=5$. One control and one treated pen sampled on the same pontoon of pens as Table 3 . Sea temperature 10.8 to $12.8^{\circ} \mathrm{C}$

\begin{tabular}{|c|c|c|c|c|c|c|}
\hline & \multicolumn{6}{|c|}{ Day } \\
\hline & 34 & 42 & 49 & 54 & 64 & 72 \\
\hline$\%$ efficacy & 91.2 & 97.8 & 97.6 & 94.0 & 95.8 & 43.8 \\
\hline \multicolumn{7}{|c|}{ Mean motile lice } \\
\hline Controls & 3.2 & 5.8 & 4.4 & 9.4 & 16.0 & 9.0 \\
\hline Treated & 0.2 & 0.2 & 0.2 & 1.0 & 0.4 & 5.4 \\
\hline \multicolumn{7}{|c|}{ Mean chalimus } \\
\hline Controls & 3.6 & 3.2 & 4.0 & 7.2 & 12.4 & 5.6 \\
\hline Treated & 0.4 & 0 & 0 & 0 & 0 & 2.8 \\
\hline
\end{tabular}


there was a decrease in chalimus on treated fish, although numbers in all 4 control pens increased.

In the autumn trial, good efficacy was achieved on treated fish although lice numbers were low on control fish throughout the trial period. Only after Day 54 was there a substantial increase in lice numbers on control fish although numbers remained low on treated fish and at Day 64 were still 95.8\% lower. By Day 77, lice numbers had increased on treated fish and were only $16.7 \%$ lower than on control fish. This compares well with an earlier field trial when lice numbers were still much lower on treated fish than on control fish at the final sampling on Day 55 (Stone et al. 2000a). More recently, an experimental tank study showed treatment with emamectin benzoate protects fish from new infestations, and iice numbers were still $88 \%$ lower on treated fish than on control fish when challenged with copepodites $62 \mathrm{~d}$ after the start of treatment (Stone et al. 2000b).

In the winter trial, even before the start of treatment, there were significant differences in lice numbers between some trial pens. This is unavoidable under field conditions and for this reason treatments should be replicated. However, all the pens had very high lice numbers at the start of the trial and lice numbers were reduced in all 4 treated groups both over time and in relation to the 4 control groups.

As in all commercial rearing pens there was considerable variation in fish weights and in each pen individual fish differed by as much as $1.5 \mathrm{~kg}$. This could result in differences in feed consumption and hence drug uptake. Despite this, no adverse effects or fish mortalities were attributed to treatment with emamectin benzoate.

Efficacy against Caligus elongatus could not be evaluated owing to low infestation levels, although in both cases numbers were lower on treated fish than on control fish. However, good efficacy of emamectin benzoate has been demonstrated against this species in earlier field trials (Stone et al. 2000a).

The hydrogen peroxide treatment carried out at the end of the winter trial was largely unsuccessful and high numbers of motile lice remained on fish in the control pens and surrounding commercial pens. In addition, hydrogen peroxide treatment does not remove chalimus stages (Treasurer \& Grant 1997. McAndrew et al. 1998), and as a result motile lice numbers rapidly recovered on control fish as the chalimus matured. Even though control fish had been treated with peroxide on Day 21, by Day 35, fish treated only with emamectin benzoate on Days 0 to 6 still had $89 \%$ fewer lice.

In both trials, only 13 and $40 \%$ of the pens on each pontoon were treated with emamectin benzoate and these treated pens were surrounded by large stocks of fish infested with sea lice and other pontoons of commercial pens in each area. Despite this large potential source of re-infestation, very good efficacy was achieved against Lepeophtheirus salmonis and numbers remained lower on treated fish for up to $64 \mathrm{~d}$. When entire sites are treated there will be less potential for re-infestation and the frequency of treatments may be reduced. In-feed treatments will permit simultaneous medication of all cages in an area, thus reducing any cross infestation that may occur during the time necessary to apply bath treatments to all cages.

Acknowledgements. The authors wish to acknowledge the help of Andrew Grant, Colin Tulip, Ian Robertson and the staff at the Marine Harvest McConnell sites at Kingairloch and Loch Duich. We would also like to thank Dr James Bron, Dr William Roy, Cam Matthews and Wendy Futter for their support and technical assistance. This work was funded by Schering-Plough Animal Health, the Scottish Salmon Growers Association and the Crown Estate Commissioners.

\section{LITERATURE CITED}

Anonymous (1998) Amelia No. 8. Veterinary Medicines Directorate, Addlestone

Erdal JI (1997) New drug treatment hits sea lice when they are most vulnerable. Fish Farming Int 24(2):9

Horst MN, Walker AN (1996) Biochemical effects of diflubenzuron on chitin synthesis in the postmolt blue crab Callinectes sapidus. J Crustac Biol 15(3):401-408

Jakobsen PJ, Holm JC (1990) Promising test with new compound against salmon lice. Norsk Fiskeoppdrett:16-18

Johnson SC, Margolis L. (1993) Efficacy of jvermectin for control of the salmon louse Lepeophtheirus salmonis on Atlantic salmon. Dis Aquat Org 17:101-105

McAndrew KJ, Sommerville C, Wootten R, Bron JE (1998) The effects of hydrogen peroxide on different life-cycle stages of the salmon louse Lepeophtheirus salmonis. $\mathrm{J}$ Fish Dis 21:221-228

Ritchie G (1996) Efficacy and action of CME-134 used as an oral treatment for the control of sea lice, Lepeophtheirus salmonis. Bull Aquacult Assoc Can 96(4):26

Ritchie G, Mordue AJ, Pike AW, Rae GH (1993) The reproductive output of Lepeophtheirus salmonis adult females in relation to seasonal variability and photoperiod. In: Boxshall GA, Defaye D (eds) Pathogens of wild and farmed fish: sea lice. Ellis Horwood, Chichester, p 153-165

Roth M, Richards R, Sommerville C (1993) Current practices in the chemotherapeutic control of sea lice infestations: a review. J Fish Dis 16:1-26

Smith PR, Moloney M, McElligott A, Clarke S, O'Brien F (1993) The efficiency of oral ivermectin in the control of sea lice infestations of farmed Atlantic salmon. In: Boxsall GA, DeFaye D (eds) Pathogens of wild and farmed fish: sea lice. Ellis Horwood, Chichester, p 296-307

Sokal R, Rohlf FJ (1981) Biometry, 2nd edn. WH Freeman \& Co, New York, p 437-440

Stone J, Sutherland IH, Sommerville CS, Richards R, Varma KJ (1999) The efficacy of emamectin benzoate as an oral treatment of sea lice, Lepeophtheirus salmonis, infestations in Atlantic salmon, Salmo salar L. J Fish Dis 22: $261-270$ 
Stone J, Sutherland IH, Sommerville CS, Richards R, Varma KJ (2000a) Field trials to evaluate the efficacy of emamectin benzoate in the control of sea lice, Lepophtheirus salmonis and Caligus elongatus, infestations in Atlantic salmon Salmo salar. Aquaculture 186: $205-219$

Stone J, Sutherland IH, Sommerville CS, Richards R, Endris RG (2000b) The duration of efficacy following oral treatment with emamectin benzoate against infestations of sea

Editorial responsibility: Wolfgang Körting,

Hannover, Germany lice, Lepophtheirus salmonis, in Atlantic salmon Salmo salar. J Fish Dis (in press)

Treasurer JW, Grant A (1997) The efficacy of hydrogen peroxide for the treatment of farmed Atlantic salmon Salmo salar L infested with sea lice (Copepoda: Caligidae). Aquaculture 148:265-275

Wadsworth S, Grant AN, Treasurer JW (1998) A strategic approach to lice control. Fish Farmer March/April 1998 $8-9$

Submitted: November 23, 1999; Accepted: March 9, 2000 Proofs received from author(s): May 17, 2000 